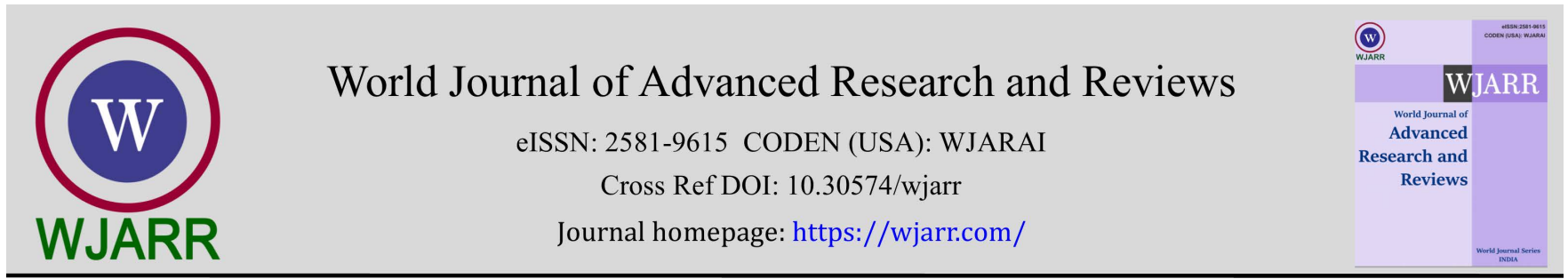

(RESEARCH ARTiCle)

\title{
Evaluation of protective potentials of Vernonia amygdalina (Bitter leaf) extracts on some selected organs of cadmium chloride-induced hypertensive albino rats
}

\author{
Henrrietta Ogadimma Nnadi ${ }^{1, *}$ and Vincent Ugochukwu Igbokwe ${ }^{2}$ \\ ${ }^{1}$ Biomedical Technology Option, School of Science Laboratory Technology, University of Port Harcourt, Choba, Rivers \\ State, Nigeria. \\ 2 Department of Human Physiology, Faculty of Basic Medical Sciences, College of Health Sciences, Nnamdi Azikiwe \\ University, Awka, Anambra State, Nigeria.
}

World Journal of Advanced Research and Reviews, 2021, 12(03), 661-673

Publication history: Received on 21 November 2021; revised on 23 December 2021; accepted on 25 December 2021

Article DOI: https://doi.org/10.30574/wjarr.2021.12.3.0087

\begin{abstract}
Many food components such as plant metabolites, have been shown to possess antioxidant activities. Vernonia amygdalina is widely consumed as vegetable for its rich array of phytochemicals and nutritional components which are attributed to its various health and medicinal benefits. The study evaluated the protective potentials of Vernonia amygdalina extracts on selected heart, Liver and Kidney of Cadmium Chloride-induced Hypertensive albino rats. The animals were induced hypertension with cadmium chloride. Total size of 50 albino rats of male and females were grouped according to sex in five different groups of ten rats per group; Control Group (1), Hypertensive Group (2), Standard group (3), methanol group (4) and n-hexane group (5). At the end of the study, blood was collected by cardiac puncture while the organs were harvested for histology test. Liver function evaluated was Aspartate Transaminase (AST), Alanine Aminotransferase (ALT) and Alanine Phosphatase (ALP). Renal function test was done following standard methods for estimation of serum Urea and Creatinine, Electrolyte and Calcium while heart, liver and kidney were subjected to histological technique. One way ANOVA was used for analysis of the collected data and was expressed as Mean \pm SEM. Result of Hypertensive group showed significant increase in sodium level $(\mathrm{p}<0.05)$ when compared with Control group. Significant decrease was observed in Sodium values of Standard drug, Vernonia amygdalina methanol and n-hexane groups when compared with the hypertensive none treated Control. Significant decrease was observed in AST values of Test groups 4 and 5 while Total bilirubin value showed significant decrease in Group 4, when hypertensive control is compared with all other Groups. Total bilirubin values of Groups 4 and 5 showed significant decrease as compared Standard to all groups. The treatment with bitter leaf resulted in a reversal of values found in untreated hypertensive group compared with the test group. Heart, liver and kidney tissues showed no lesion or inflammation in all the groups except hypertensive none treated group that showed distorted patchy necrotic area in the histology test. The results of this study suggest that Vernonia amygdalina possesses protective potential against Cadmium chloride induced hypertension in albino rats.
\end{abstract}

Keywords: Bitter leaf; Protective; Hypertension; Disease; Vernonia amygdalina

\section{Introduction}

Food spices have numerous functions such as food flavoring, antioxidant, medicinal, and preservative functions [1-2]. Nutraceuticals from Tetracapedium conophorum have been reported to protect against cadmium chloride-induced hypertension [3]. Vernonia amygdalina (Bitter leaf) is a green leafy vegetable and contains nutrients which are important to the body as a protective and regulatory agents [4]. Vernonia amygdalina has been shown to contain

\footnotetext{
${ }^{*}$ Corresponding author: Henrrietta Ogadimma Nnadi

Biomedical Technology Option, School of Science Laboratory Technology, University of Port Harcourt, Choba, Rivers State, Nigeria. 
phosphorus, ascorbic acid, iron, B-carotene, Calcium, fiber, water and other nutrients and also reported to possess phytochemical constituents such as alkaloids, saponins, tannins, steroid, glucosides, flavonoids, glycosides [5]. Vernonia amygdalina commonly called bitter leaf is a multipurpose and rapid regenerating shrub of 2 to $10 \mathrm{~m}$ tall and leaves of about $6 \mathrm{~mm}$ in diameter which is consumed either as a vegetable for cooking African soups or the aqueous extracts taken as tonics for the treatment of various illnesses [6]. The plant has been called different ethnic names in Nigeria such as Onugbu or Olugbu (Igbo), Kiriologbo (Ijaw), Shiwaka (in Hausa), Ewuro (Yoruba) and also Ndole in Cameroun [7, 8]. Vernonia amygdalina is an abundant farming vegetable and fodder tree in Nigeria [9] whose leaves are used as soup condiment and as vegetable. The leaves and roots were reported to have been used in the treatment of fever, kidney disorder, hiccups, stomach discomfort such as increased rat uterine motility, rabbit jejenum contraction and also protect against kidney impairment [10-15]. Some studies have shown that this antioxidant-rich food product have potential bioactive substances that exhibit protective properties [16-22]. Epidemiological findings have shown that antioxidants can keep back the development of degenerative diseases such as hypertension, coronary heart diseases, cancer, obesity, premature aging, type 2 diabetes, and inflammatory diseases [23]. Vernonia amygalina has been reported to also exhibit anti-helmitic and anti-malaria properties [24], as well as anti-tumorigenic properties [25]. Vernonia amygdalina has also been used for both therapeutic and nutritional purposes, it has been shown to contain significant quantities of Calcium, iron, potassium, phosphorous, manganese, copper and cobalt. Heart, Kidney and liver diseases are serious health issues, especially for the central roles they play in metabolic homeostasis and xenobiotic transformations. A number of physiological mechanisms are involved in the maintenance of normal blood pressure, and their derangement may play a part in the development of essential hypertension. Report has it that the incidence of cardiovascular diseases can be lowered by application of phytosterols through serum cholesterol levels reducing actions, but that of hypertension has not been shown much report. Two major risk factors of cardiovascular diseases (hypertension and dyslipidaemia) was reported to contribute to the progression and pathogenesis of cardiovascular disease both synergistically and individually [26]. The search for alternative ways of treatment of such derangement using nutraceuticals could be useful in management, prevention, control and treatment of cardiovascular, renal and hepatic diseases [27]. Hence evaluation of nutraceuticals from Vernonia amygdalina may possess protective potentials which may as well help to scavenge this free-radicals and offers health benefit to the cadmium chloride-induced hypertensive rats.

\section{Material and methods}

\subsection{Identification and Preparation of Plant Materials:}

Fresh bitterleaf (Vernonia amygdalina) was purchased by the researcher and was identified by Dr. Chimezie Ekeke of the Department of Plant Science and Biotechnology, University of Port Harcourt with identification number UPH/P/308. The leaf was washed, completely drained, separately coarse and was allowed to air-dry at room temperature. It was monitored and at the end of the two weeks, large kilogram of fully dried leaves were grinded into powdered form with the use of electrical blender. Extraction of the blended leaves of Vernonia amygdalina was done by the use of Rotary Vane Extraction with solvents methanol and n-hexane. Extraction was done in two stages - first stage involved crude extraction with ethanol and the second stage involved further extraction with Whatman No 1 filter paper. The ethanol were evaporated to semi-solid state at $80^{\circ} \mathrm{C}$ within two days. The aqueous filtration evaporated to semi-solid state by the use of rotary evaporator. Each $500 \mathrm{~g}$ of blended forms was caused to flow back in two (2) liter volume of methanol solvent (1:4). Basic phytochemical screening was done on the leaves using standard methods.

\section{Animal experiment}

Number of animals used in this study were a total of 50 albino rats (30 females, 20 males). The animals were breed at the Animal House of the Department of Human Physiology, Nnamdi Azikiwe University Okofia Campus. They were acclimatized for 14 days, during which UgoBasil tail-cuff pressure measurement was implored to measure their blood pressure (this enabled the animals acclimatized with the equipment avoiding unnecessary agitation of the first entrance of the rat into the cuff) before they were induced and treated. The albino rats were housed in rat cage of normal room temperature, well ventilated with 12 hour lightened 12 hour darkness cycle. Feed and water were purchased from Pfizer Nigeria limited feeds Benin City for the study. The albino rats were used in accordance with NIH Guide for the care and use of laboratory animals revised Publication. Standard Operation Procedures (SOPs) were also applied (Helsinki Declaration). Histological study of the heart, kidney and liver were done while renal and liver function test was also done.

- Group 1: Control group were rats which were not induced nor treated with any extract but were only fed with animal feed and water daily throughout the study period. 
- Group 2. Hypertensive control group were induced with Cadmium chloride, confirmed hypertensive, were not treated throughout the study but were fed with animal feed and water only.

- Group 3: Standard drug group were induced with cadmium chloride and were treated with Nifedipine (a known hypertensive drug). The animals were also fed with feed and water.

- Group 4: Cadmium Chloride induced hypertensive group treated with methanol Vernonia amygdalina leaf extract.

- Group 5: Cadmium Chloride induced hypertensive group treated with n-Hexane Vernonia amygdalina leaf extract.

At the end of the 4 weeks of treatment, the animals were sacrificed, blood collected by cardiac puncture into sodium fluoride and EDTA sample bottles for biochemical analysis. The organs of each animal in each group were harvested into a plane sample bottle for histopathology analysis on the kidney, heart and liver each study group [3].

\subsection{Measurement of biochemical parameters [3]}

The biochemical parameters analysed (kidney function test) on serum electrolyte were sodium, potassium, chloride, urea and creatinine. Liver function test were AST, ALT, alkaline phosphatase, metabolic system test and total protein, albumin, total bilirubin, conjugate bilirubin were also analysed. We considered and selected the above indices for hypertension analysis as was recommended by Harrison's Principles of Internal Medicine [28]

\subsection{Sodium (spectrophotometric method)}

Test tubes were labelled as blank, standard, control, test sample. Then $1 \mathrm{ml}$ of filtrate reagent were pipetted to all tubes.

$50 \mu \mathrm{l}$ of sample were added to all tubes and distilled water to the blank, shook all tubes vigorously and mixed continuously for three minutes. Tubes were centrifuged at high speed (1500g) for 10 minutes. The supernatant were tested as described below taking care not to disturb the protein precipitate

\subsubsection{Colour developer}

Labelled test tubes corresponding to the above filtrate tubes, pipette $1.0 \mathrm{ml}$ acid reagent to all tubes, added $50 \mu \mathrm{l}$ of colour reagent to all tubes and mixed, zero the spectrophotometer with distilled water at $550 \mathrm{~nm}$, read the absorbance of all tubes and recorded (unit in $\mathrm{meg} / \mathrm{l}$ )

\subsection{Potassium reagent (Dpectophotometric method) [3]}

Test tubes were labelled standard, control, test sample, blank, then pipetted $1 \mathrm{ml}$ of potassium reagent to all tubes. Added $0.01 \mathrm{ml}$ of samples to respective tubes, mixed and allowed to stand at room temperature for 3 minutes. Turned the wavelength of spectrophotometer on to $500 \mathrm{~nm}$, zero spectrophotometer with reagent blank. Read the absorbance of all tubes and recorded.

\subsection{Chloride (automated method)}

Test tubes were labelled blank, calibrator, test sample. Pipetted $1.5 \mathrm{ml}$ chloride reagent to each tubes. Added $0.01 \mathrm{ml}$ of calibrator or sample to respective tubes and mixed. Incubated at room temperature for five minutes. Spectrophotometer was fixed for $480 \mathrm{~nm}$ and zero with reagent blank. Wavelength of $520 \mathrm{~nm}$ was used. Then read the absorbance of all tubes and recorded in Meq/l.

\subsection{Urea (Manual Spectrophotometry Method)}

Test tubes were labelled blank, standard, test sample. $10 \mu \mathrm{l}$ of urea reagent was pipetted to reagent tubes. All tubes were mixed and incubated at the temperature of $37^{\circ} \mathrm{C}$ for 10 minutes. Spectrophotometer wavelength was fixed at $546 \mathrm{~nm}$ and temperature to $37^{\circ} \mathrm{C}$. Pipetted $2.5 \mathrm{ml}$ of water, standard and sample to the cuvette labelled blank, standard and test sample respectively. Immediately mixed and incubated at $37^{\circ} \mathrm{C}$ temperature for 15 minutes. Read the absorbance of the sample and standard against the blank and recorded.

\subsection{Cratinine (Spectrophotometry Method)}

Test tubes were labelled blank, calibrator, text sample. $2 \mathrm{ml}$ of reagent was pipetted into each tube. Pipetted $0.1 \mathrm{ml}$ of calibrator into cuvette tubes respectively and mixed. Incubated at the temperature of $25-37^{\circ} \mathrm{C}$. Spectrophotometer was 
fixed at 492nm and zero with reagent, mixed and Absorbance $A_{1}$, standard and sample were read after 30 seconds. Read absorbance $A_{2}$ of standard and samples at exactly 2 minutes.

\subsection{AST (Aspartate Aminotransferase): (Spectrophotometry Method)}

Test tubes were labelled, blank, standard and test sample. $0.1 \mathrm{M}$ of sample were pipetted into all test tubes. $0.5 \mathrm{ml}$ of reagent (1) buffer was added to all test tubes, mixed and incubated for exactly 30 minutes at $37^{\circ} \mathrm{C}$. Spectrophotometer wavelength was fixed at $\mathrm{Hg} 546 \mathrm{~nm}$. $0.5 \mathrm{ml}$ of $\mathrm{R}_{2}$ (2.4 dinitrophenylhydrazine) were pipetted to the cuvette test tubes respectively, $0.1 \mathrm{ml}$ sample were pipetted and mixed. It was allowed to stand for 20 minutes at $20^{\circ} \mathrm{C}$ to $25^{\circ} \mathrm{C}$. Then added $5.0 \mathrm{ml}$ of Sodium Hydroxide and mixed. After 5 minutes, the absorbance of the sample $\left(\mathrm{A}_{\text {sample }}\right)$ were read against the sample blank and recorded.

\subsection{ALT (Alamine Aminotransferase): (Spectrophotometry Method)}

Test tubes were labelled; blank, test sample, standard. $0.5 \mathrm{ml}$ reagent were pipetted into test tubes. Added $0.1 \mathrm{ml}$ sample to all tubes, mixed and incubated at $37^{\circ} \mathrm{C}$ for exactly 30 minutes. Spectrophotometer was set at wavelength of $\mathrm{Hg} 546 \mathrm{~nm}$. Pipetted $0.5 \mathrm{ml}$ solution into cuvette labeled; blank, test sample, standard. $5.0 \mathrm{ml}$ of sodium hydroxide was added, mixed and allowed to stand for $20 \mathrm{~min}$ at $20-25^{\circ} \mathrm{C}$. Read the absorbance of sample (Asample) against the reagent blank after 5minutes.

\subsection{Alkaline Phosphates (Spectrophotometry Method)}

Brought reagents and the analyzer to $37^{\circ} \mathrm{C}$ temperature. Labelled test tubes, blank, standard, test sample. $1.0 \mathrm{ml}$ of deionized water was pipetted into test tubes. 1 drop of substrate was added into all tubes, mixed and incubated at $37^{\circ} \mathrm{C}$ for 5 minutes. Spectrophotometer wavelength was fixed at $550 \mathrm{~nm} .0 .1 \mathrm{ml}$ was pipetted into corresponding test tubes and cuvettes of $1 \mathrm{~cm}$ thermostat. Mixed, incubated at the temperature of $37^{\circ} \mathrm{C}$ for 20 minutes. Then colored developer was added, allowed to stand at minimum of 1 hour, read and recorded the result.

\subsection{Total Protein (TP): (Spectrophotometry Method).}

Test tubes were labelled; blank, standard, test sample. $0.02 \mathrm{ml}$ of distilled water were pipetted into cuvette test tubes. $0.02 \mathrm{ml}$ standard of CAL were added to all test tubes. Set the spectrophotometer wavelength of $\mathrm{Hg} 546 \mathrm{~nm}$ at the temperature $20-25 \mathrm{C}$. Then $0.02 \mathrm{ml}$ of serum was added, mixed and incubated for 30 mintes at the temperature of $20^{\circ} \mathrm{C}$ $-25^{\circ} \mathrm{C}$. Then measured the absorbance of the sample $\left(\mathrm{A}_{\text {sample}}\right)$ and the standard $\left(\mathrm{A}_{\text {standard }}\right)$ against the reagent blank and record.

\subsection{Albumin (ALB): (Spectrophotometry Method)}

Test tubes were labekked; blank, standard, test sample. $0.01 \mathrm{ml}$ of distilled water was pipetted into test tubes. $0.01 \mathrm{ml}$ of standard were added (cal). Spectrophotometer wavelength was set at $630 \mathrm{~nm}$ at the temperature of $20-25^{\circ} \mathrm{C}$. Then pipetted into corresponding cuvette test tubes $0.01 \mathrm{ml}$ of serum, add ed $3.00 \mathrm{ml} \mathrm{BCG}$ (bromocresol green) reagent. Mixed and incubated for 5 minutes at temperature of $20-25{ }^{\circ} \mathrm{C}$. Measured the absorbance of the sample $\left(\mathrm{A}_{\text {sample }}\right)$ and the standard (Astandard) against the reagent blank and recorded.

\subsection{Total bilirubrin (Spectrophotometry Method)}

Test tubes were labelled; blank, standard, test tubes. Distilled water was pipetted into cuvettes, added (R1) sulphanilic acid, (R2) Nitrite with (R3) caffeine and sample. Allowed to stand for 10 minutes at $25^{\circ} \mathrm{C}$. Spectrophotometer wavelength was fixed at 578nm. Then added (R4) tartrate, mixed and allowed to stand for 5-30 minutes at 20-25C. Read by measuring the absorbance of the sample against the sample blank $\left(A_{t b}\right)$ and recorded.

\subsection{Histological study: (hematoxylin and eosin (H\&E) staining techniques)}

Harvested heart, liver and kidney tissues were fixed in $10 \%$ formalin solution and was embedded in melted paraffin wax. Hematoxylin and Eosin (H\&E) histological techniques were used. An Olympus light microscope were used for photomicrography on the mounted slide and was captured with Kodak digital camera. 


\section{Results and discussion}

\subsection{Effects of Serum Electrolyte, Urea and Creatinine levels}

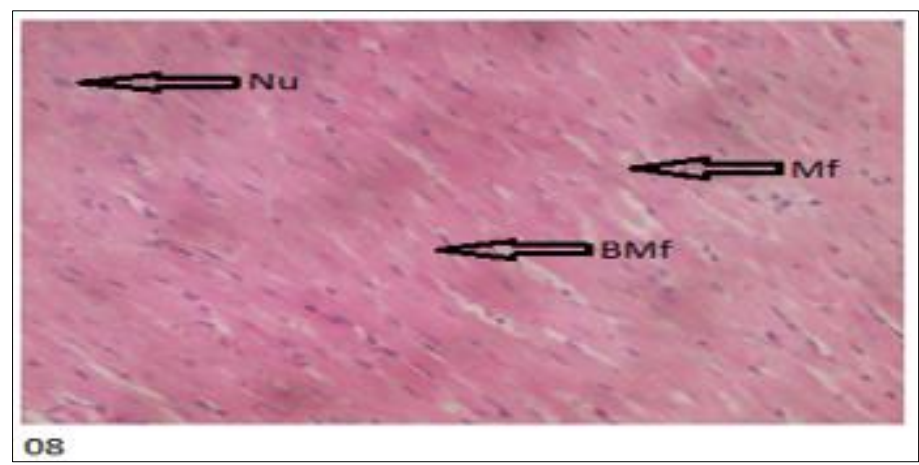

Figure 1 Photomicrograph of Cardiac muscle x400 H\&E stained Group 1 - Control [3]

Showing histologically normal cardiac muscle

- Homogeneous muscle fiber (MF) diameter, with intact sarcolemma.

- Peripherally placed nuclei (Nu)

- Branching cardiac muscle fiber (BMF)

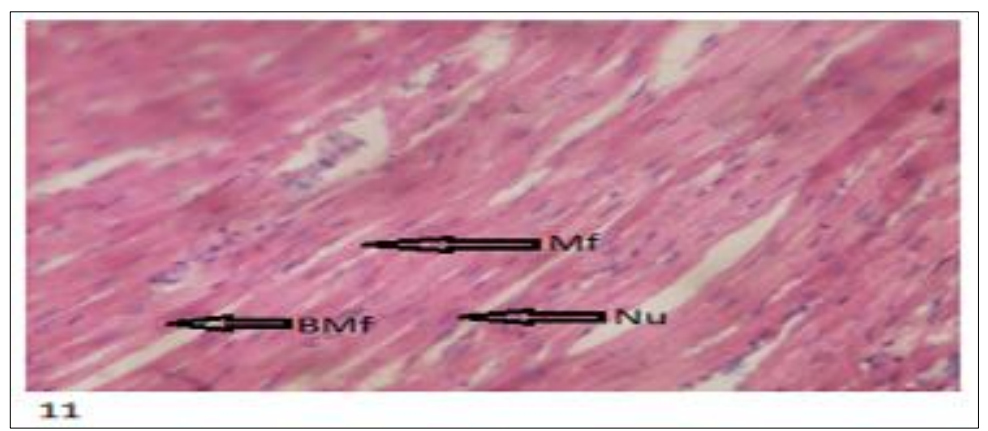

Figure 2 Photomicrograph of Cardiac muscle (x400). H/E stain for group 4 -Vernonia amygdalina methanol extract

Showing histologically normal cardiac muscle

- Homogeneous muscle fiber (MF) diameter, with intact sarcolemma.

- Branching cardiac muscle fiber (BMF).

- Peripherally placed nuclei (Nu)

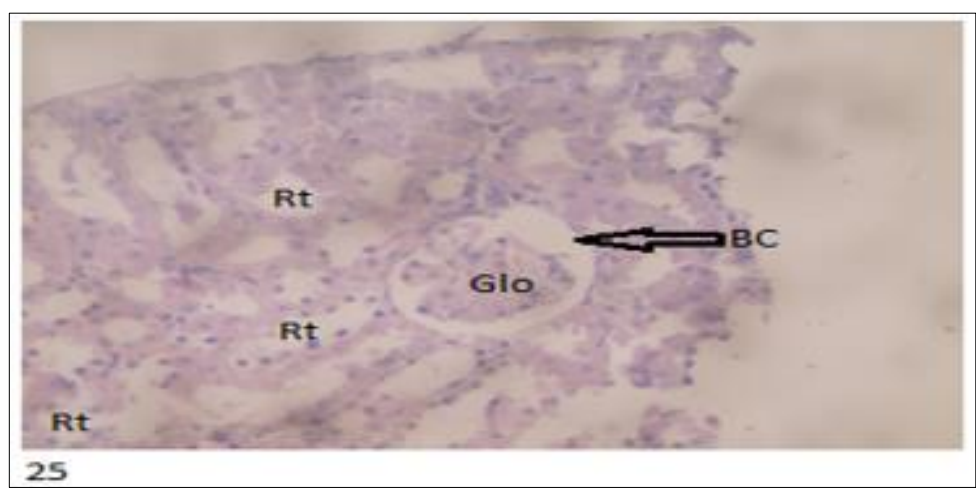

Figure 3 Photomicrograph of Kidney x400, H\&E stained Group 1 - Control [3] 
Histologically normal kidney showing

- Bowman's capsular spaces (BC)

- Glomerular tuft (Glo) containing mesengial cells, capillaries and mesengial matrix.

- $\quad$ Renal tubules (Rt).

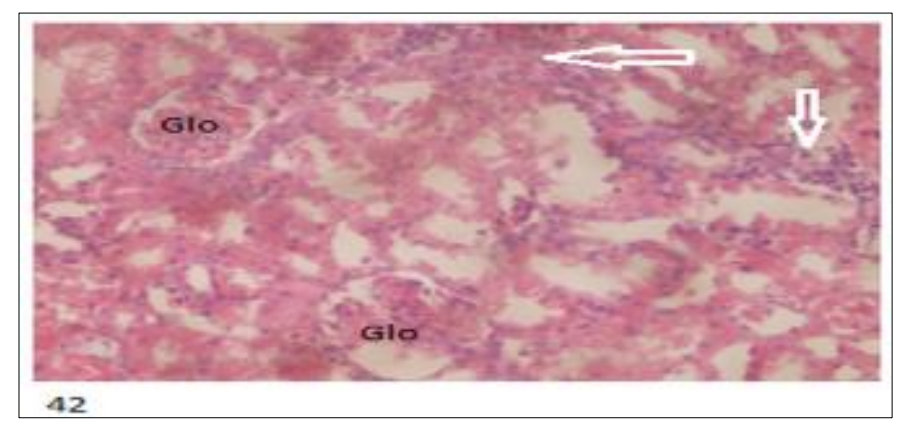

Figure 4 Photomicrograph of Kidney x400, H\&E stained Group 2-Hypertensive group [3]

Histologically distorted kidney showing

- Dilated capillaries

- Inflammatory cells

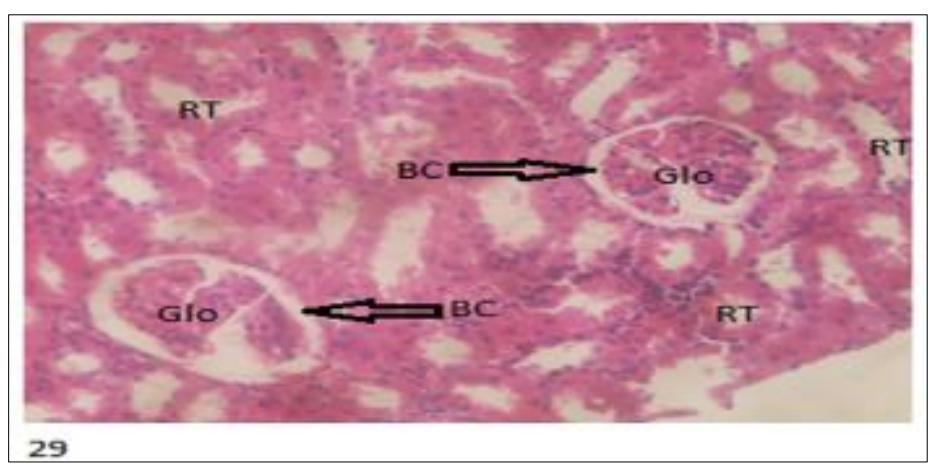

Figure 5 Photomicrograph of Kidney x400, H\&E stained Group 3-Standard Drug Group [3]

Histologically normal kidney showing

- Glomerular tuft (Glo) containing mesengial cells, capillaries and mesengial matrix.

- Bowman"s capsular spaces (BC)

- Renal tubules (Rt)

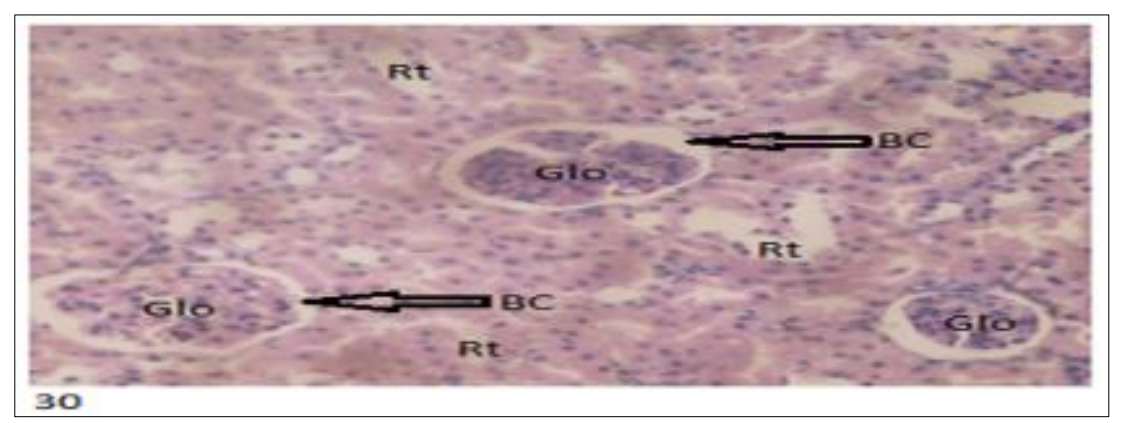

Figure 6 Photomicrograph of Kidney, x400 H\&E stained Group 4 -Vernonia amygdalina methanol 
Histologically normal kidney showing

- Glomerular tuft (Glo) containing mesengial cells, capillaries and mesengial matrix.

- Renal tubules (Rt).

- Bowman's capsular spaces (BC)

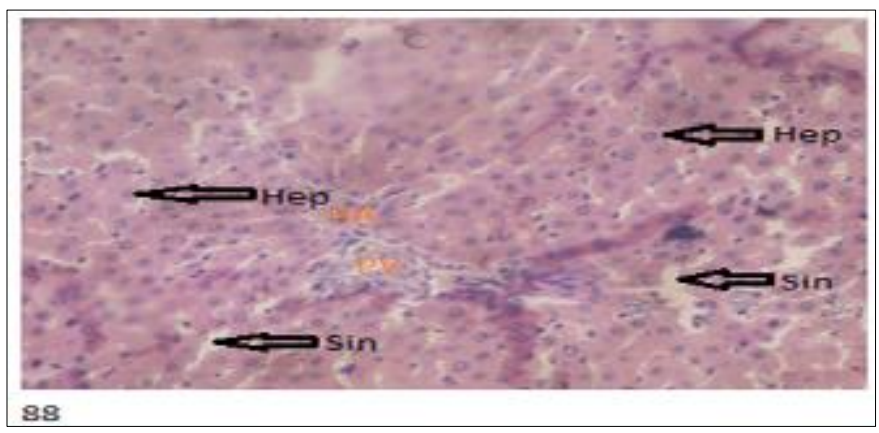

Figure 7 Photomicrograph of Liver x400, H\&E stained Group 1 - Control [3]

Histologically normal Liver showing

- Cords of normal hepatocytes (Hep)

- Hepatic artery (HA) and portal vein (PV).

- $\quad$ Sinusoids (sin) containing capillaries and Yon Kupffer cells

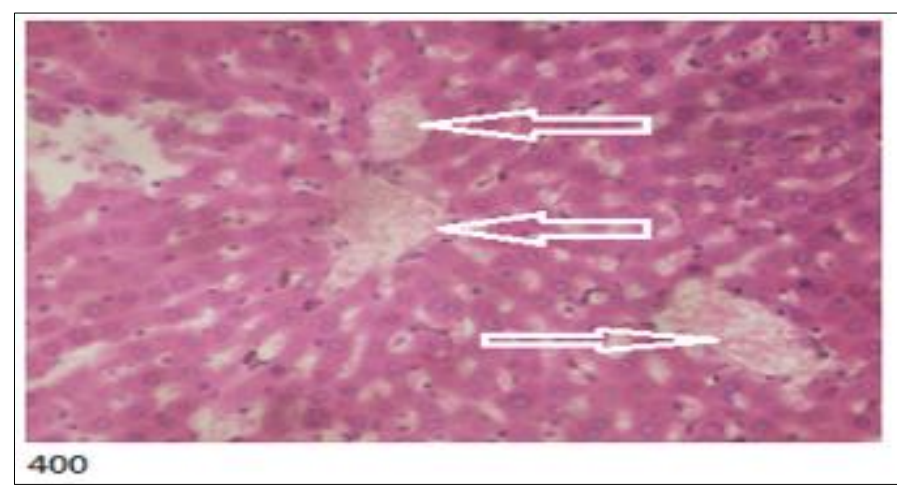

Figure 8 Photomicrograph of Liver $\times 400$, H\&E stained Group 2- Hypertensive Group [3]

Histologically distorted liver showing

- $\quad$ patchy necrotic areas arrowed

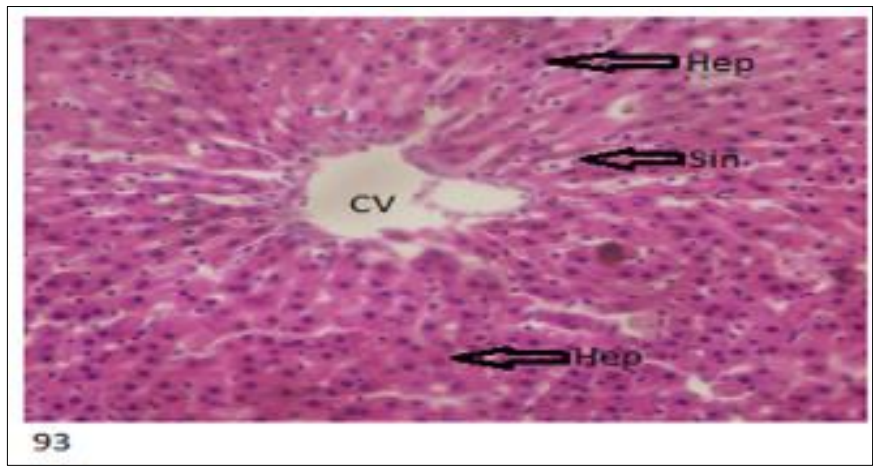

Figure 9 Photomicrograph of Liver, $\times 400$ H\&E stained Group3 - Standard Drug [3] 
Histologically normal liver showing

- Patent central vein

- Sinusoid (Sin)

- Normal Hepatocytes

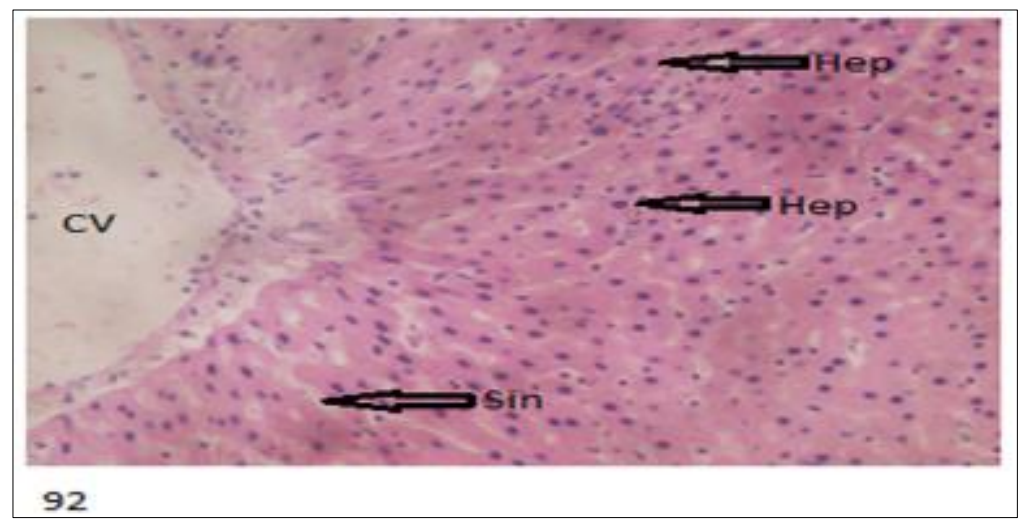

Figure 10 Photomicrograph of Liver, $\times 400$ H\&E stained Group 4 -Vernonia amygdalina-methanol

Histologically normal liver showing

- Patent central vein (CV)

- Cords of normal hepatocytes (Hep)

- Sinusoids (Sin)

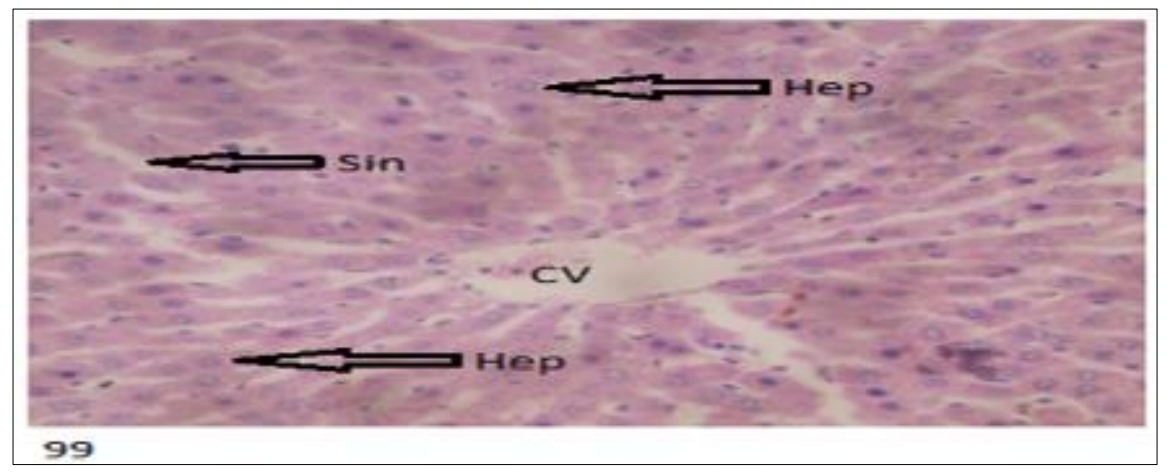

Figure 11 Photomicrograph of Liver, $\times 400$ H\&E stained Group 5 -Vernonia amygdalina- $n$-hexane

Histologically normal liver showing

- Sinusoids (Sin) containing capillaries and Kupffer cells.

- Patent central vein (CV)

Cords of normal hepatocytes (Hep) 
Table 1 Electrolyte values of the Control Group and the different Test Groups

\begin{tabular}{|c|c|c|c|c|c|c|c|c|c|c|c|c|}
\hline & $\begin{array}{l}\text { Sodium } \\
(\mathrm{mEq} \backslash \mathrm{L}) \\
\text { Mean } \pm \text { SEM }\end{array}$ & $\begin{array}{l}\text { P- } \\
\text { VALUE }\end{array}$ & $\begin{array}{l}\text { Potassium } \\
(\mathrm{mEq} \backslash \mathrm{L}) \\
\operatorname{Mean} \pm \mathrm{SEM}\end{array}$ & $\begin{array}{l}\text { P- } \\
\text { VALUE }\end{array}$ & Bicarbonate & $\begin{array}{l}\text { P- } \\
\text { VALUE }\end{array}$ & $\begin{array}{l}\text { Chloride } \\
(\mathrm{mEq} \backslash L)\end{array}$ & $\begin{array}{l}\text { P- } \\
\text { VALUE }\end{array}$ & $\begin{array}{l}\text { Urea } \\
(\mathrm{mEq} \backslash L)\end{array}$ & $\begin{array}{l}\text { P- } \\
\text { VALUE }\end{array}$ & $\begin{array}{l}\text { Creatinine } \\
(\mu \mathrm{mol} \backslash \mathrm{L})\end{array}$ & $\begin{array}{l}\text { P- } \\
\text { VALUE }\end{array}$ \\
\hline 1 & $236.33 \pm 47.55$ & & $8.52 \pm 2.17$ & & $38.83 \pm 2.28$ & & $101.29 \pm 10.67$ & & $5.28 \pm 0.35$ & & $184.84 \pm 99.05$ & \\
\hline 2 & $443.96 \pm 34.95$ & $0.01 *$ & $21.80 \pm 1.44$ & $0.00^{*}$ & $30.72 \pm 4.56$ & 0.10 & $216.63 \pm 55.48$ & $0.02^{*}$ & $4.26 \pm 0.63$ & 0.20 & $212.42 \pm 47.52$ & 0.73 \\
\hline 3 & $293.73 \pm 67.95$ & 0.46 & $21.36 \pm 2.73$ & $0.01^{*}$ & $42.73 \pm 2.44$ & 0.45 & $127.86 \pm 18.86$ & 0.60 & $4.62 \pm 0.63$ & 0.41 & $81.55 \pm 5.04$ & 0.22 \\
\hline 4 & $280.44 \pm 38.90$ & 0.56 & $3.42 \pm 0.98$ & 0.15 & $34.92 \pm 3.87$ & 0.43 & $160.66 \pm 28.32$ & 0.23 & $5.42 \pm 0.32$ & 0.85 & $77.09 \pm 1.01$ & 0.19 \\
\hline 5 & $261.89 \pm 57.98$ & 0.74 & $13.59 \pm 3.58$ & 0.15 & $38.51 \pm 3.41$ & 0.95 & $190.79 \pm 167.50$ & 0.07 & $4.32 \pm 0.75$ & 0.23 & $80.26 \pm 8.62$ & 0.21 \\
\hline
\end{tabular}

Table 2 Electrolyte values of the Hypertensive Group and the different Test Groups

\begin{tabular}{|c|c|c|c|c|c|c|c|c|c|c|c|c|}
\hline & $\begin{array}{l}\text { Sodium } \\
(\mathrm{mEq} \backslash \mathrm{L}\} \\
\operatorname{Mean} \pm \text { SEM }\end{array}$ & P-Value & $\begin{array}{l}\text { Potassium } \\
(\mathrm{mEq} \backslash \mathrm{L}\} \\
\operatorname{Mean} \pm \mathrm{SEM}\end{array}$ & & Bicarbonate & $\begin{array}{l}\text { P- } \\
\text { Value }\end{array}$ & $\begin{array}{l}\text { Chloride } \\
(\mathrm{mEq} \backslash \mathrm{L}\}\end{array}$ & $\begin{array}{l}\text { P- } \\
\text { Value }\end{array}$ & Urea & $\begin{array}{l}\text { P- } \\
\text { Value }\end{array}$ & $\begin{array}{l}\text { Creatinine } \\
\text { ( } \mu \mathrm{mol} \backslash \mathrm{L}\}\end{array}$ & $\begin{array}{l}\text { P- } \\
\text { Value }\end{array}$ \\
\hline 2 & $443.96 \pm 34.95$ & & $21.80 \pm 1.44$ & & $30.72 \pm 4.56$ & & $216.63 \pm 55.48$ & & $4.62 \pm 0.63$ & & $81.55 \pm 5.04$ & \\
\hline 3 & $293.73 \pm 67.95$ & $0.05^{*}$ & $21.36 \pm 2.73$ & 0.89 & $42.73 \pm 2.44$ & $0.01^{*}$ & $127.86 \pm 18.86$ & 0.08 & $5.42 \pm 0.32$ & 0.99 & $77.09 \pm 1.01$ & 0.11 \\
\hline 4 & $280.44 \pm 38.90$ & $0.03^{*}$ & $3.42 \pm 0.98$ & $0.00^{*}$ & $34.92 \pm 3.87$ & 0.39 & $160.66 \pm 28.32$ & 0.25 & $5.55 \pm 0.47$ & 0.99 & $62.97 \pm 4.88$ & 0.09 \\
\hline 5 & $261.89 \pm 57.98$ & $0.01^{*}$ & $13.59 \pm 3.58$ & $0.02^{*}$ & $38.51 \pm 3.41$ & 0.11 & $190.79 \pm 167.50$ & 0.59 & $4.32 \pm 0.75$ & 1.00 & $90.93 \pm 5.52$ & 0.10 \\
\hline
\end{tabular}

Table 3 Electrolyte values of the Standard Drug Group and the different Test Groups

\begin{tabular}{|c|c|c|c|c|c|c|c|c|c|c|c|c|}
\hline & $\begin{array}{l}\text { Sodium } \\
(\mathrm{mEq} \backslash \mathrm{L}\} \\
\text { Mean } \pm \text { SEM }\end{array}$ & $\begin{array}{l}\text { P- } \\
\text { VALUE }\end{array}$ & $\begin{array}{l}\text { Potassium } \\
(\mathrm{mEq} \backslash \mathrm{L}\} \\
\text { Mean } \pm \\
\text { SEM }\end{array}$ & $\begin{array}{l}\text { P- } \\
\text { VALUE }\end{array}$ & Bicarbonate & $\begin{array}{l}\text { P- } \\
\text { VALUE }\end{array}$ & $\begin{array}{l}\text { Chloride } \\
(\mathrm{mEq} \backslash L\}\end{array}$ & $\begin{array}{l}\text { P- } \\
\text { VALUE }\end{array}$ & Urea & & $\begin{array}{l}\text { Creatinine } \\
(\mu \mathrm{mol} \backslash \mathrm{L}\}\end{array}$ & $\begin{array}{l}\text { P- } \\
\text { VALUE }\end{array}$ \\
\hline 3 & $280.44 \pm 38.90$ & & $21.36 \pm 2.73$ & & $42.73 \pm 2.44$ & & $127.86 \pm 18.86$ & & $5.42 \pm 0.32$ & & $77.09 \pm 1.01$ & \\
\hline 4 & $220.49 \pm 55.57$ & 0.86 & $3.42 \pm 0.98$ & $0.00^{*}$ & $34.92 \pm 3.87$ & 0.12 & $160.66 \pm 28.32$ & 0.99 & $5.55 \pm 0.47$ & 0.99 & $62.97 \pm 4.88$ & 0.957 \\
\hline 5 & $189.69 \pm 53.12$ & 0.68 & $13.59 \pm 3.58$ & $0.03^{*}$ & $38.51 \pm 3.41$ & 0.40 & $190.79 \pm 167.50$ & $0.01^{*}$ & $4.32 \pm 0.75$ & 0.99 & $90.93 \pm 5.52$ & 0.98 \\
\hline
\end{tabular}


Table 4 Comparison of the Markers of Control Group and the Different Test Groups

\begin{tabular}{|c|l|l|c|c|c|c|c|}
\hline & ALT & AST & ALK.PHOS (U/L) & TOTAL PROTEIN & ALBUMIN & TOTAL BILIRUBIN & CONJ Bilirubin \\
\hline 1 & $53.56 \pm 11.17$ & $64.00 \pm 10.09$ & $48.97 \pm 0.27$ & $21.05 \pm 1.93$ & $5.45 \pm 0.16$ & $0.62 \pm 0.15$ & $0.45 \pm 0.09$ \\
\hline 2 & $83.00 \pm 4.41$ & $76.20 \pm 8.70$ & $48.83 \pm 0.24$ & $21.69 \pm 2.16$ & $5.24 \pm 0.31$ & $0.88 \pm 0.15$ & $0.36 \pm 0.11$ \\
\hline 3 & $72.44 \pm 7.83$ & $64.22 \pm 8.03$ & $49.21 \pm 0.20$ & $22.57 \pm 1.99$ & $5.60 \pm 0.26$ & $1.09 \pm 0.13$ & $0.30 \pm 0.03$ \\
\hline 4 & $85.90 \pm 5.03$ & $49.90 \pm 4.99$ & $48.36 \pm 0.40$ & $20.24 \pm 1.91$ & $5.50 \pm 0.22$ & $0.30 \pm 0.06$ & $0.63 \pm 0.17$ \\
\hline 5 & $73.30 \pm 10.27$ & $44.20 \pm 9.88$ & $49.20 \pm 0.17$ & $21.29 \pm 1.99$ & $5.14 \pm 0.39$ & $0.71 \pm 0.06$ & $0.39 \pm 0.08$ \\
\hline
\end{tabular}

Table 5 Comparison of Markers of the Hypertensive Group and the Different Test Groups

\begin{tabular}{|c|l|l|c|c|c|c|c|}
\hline & ALT & AST & ALK.PHOS (U/L) & TOTAL PROTEIN & ALBUMIN & TOTAL BILIRUBIN & CONJ Bilirubin \\
\hline 2 & $83.00 \pm 4.41$ & $76.20 \pm 8.70$ & $48.83 \pm 0.24$ & $21.69 \pm 2.16$ & $5.24 \pm 0.31$ & $0.88 \pm 0.15$ & $0.36 \pm 0.11$ \\
\hline 3 & $72.44 \pm 7.83$ & $64.22 \pm 8.03$ & $49.21 \pm 0.20$ & $22.57 \pm 1.99$ & $5.60 \pm 0.26$ & $1.09 \pm 0.13$ & $0.30 \pm 0.03$ \\
\hline 4 & $85.90 \pm 5.03$ & $49.90 \pm 4.99^{*}$ & $48.36 \pm 0.40$ & $20.24 \pm 1.91$ & $5.50 \pm 0.22$ & $0.30 \pm 0.06^{*}$ & $0.63 \pm 0.17$ \\
\hline 5 & $73.30 \pm 10.27$ & $44.20 \pm 9.88^{*}$ & $49.20 \pm 0.17$ & $21.29 \pm 1.99$ & $5.14 \pm 0.39$ & $0.71 \pm 0.06$ & $0.39 \pm 0.08$ \\
\hline
\end{tabular}

There was significant decrease in the groups 4 and 5 in the AST values significant decrease in the total bilirubin values of groups 4

Table 6 Comparison of Markers of the Standard Drug Group and the Different Test Groups

\begin{tabular}{|c|l|l|l|l|c|c|c|}
\hline & ALT & AST & $\begin{array}{l}\text { ALK.PHOS } \\
\text { (U/L) }\end{array}$ & $\begin{array}{l}\text { TOTAL } \\
\text { PROTEIN }\end{array}$ & ALBUMIN & $\begin{array}{l}\text { TOTAL } \\
\text { BILIRUBIN }\end{array}$ & $\begin{array}{l}\text { CONJ } \\
\text { Bilirubin }\end{array}$ \\
\hline 3 & $72.44 \pm 7.83$ & $64.22 \pm 8.03$ & $49.21 \pm 0.20$ & $22.57 \pm 1.99$ & $5.60 \pm 0.26$ & $1.09 \pm 0.13$ & $0.30 \pm 0.03$ \\
\hline 4 & $85.90 \pm 5.03$ & $49.90 \pm 4.99$ & $48.36 \pm 0.40$ & $20.24 \pm 1.91$ & $5.50 \pm 0.22$ & $0.30 \pm 0.06^{*}$ & $0.63 \pm 0.17^{*}$ \\
\hline 5 & $73.30 \pm 10.27$ & $44.20 \pm 9.88$ & $49.20 \pm 0.17$ & $21.29 \pm 1.99$ & $5.14 \pm 0.39$ & $0.71 \pm 0.06^{*}$ & $0.39 \pm 0.08$ \\
\hline
\end{tabular}

Significant decrease in the total bilirubin levels of groups 4 and 5; There was significant decrease in the conjugated bilirubin levels of groups 4 


\section{Discussion}

A number of physiological mechanisms are involved in the maintenance of normal blood pressure, and their derangement may play a part in the development of essential hypertension. In this study, an evaluation of protective potentials of Vernonia amygdalina methanol and n-hexane extracts was evaluated on some selected heart, liver and kidney of cadmium chloride-induced hypertensive albino rats, putting into consideration the fact that utilization of natural plants (leaves, nuts, seeds, and herbs) may meet the growing need for value addition regarding the maintenance of physiological condition, prevention of disease and health care promotion. Measurement of electrolyte parameters, liver markers and kidney function are some of the sure ways of diagnosis of cardiovascular diseases. The result in this study showed significant increase of sodium value in Table 1 for the hypertensive (untreated) group as the control was compared with all groups. This may have been due to volume overload and sodium retention which reached its climax as hypertension [3; 29]. Table 2 shows the comparison of Hypertensive group to other groups with significant decrease in sodium level of the Standard drug, Vernonia amygdalina methanol and Vernonia amygdalina n-hexane Groups (Groups 3, 4 and 5). This significant decrease suggest that Vernonia amygdalina have reversal potentials on sodium volume overload and sodium retention as observed in cadmium chloride induced hypertensive group [6]. Table 2 also showed significant decrease in potassium in the test groups 4 and 5 which signifies hypokalaemia. Vernonia amygdalina is seen to cause loss of potassium maybe in urine (excessive urination known as water pill/diuretics). This type ameliorate heart disease or high blood pressure, but too much potassium in the blood can damage the heart and cause a heart attack. Vernonia amygdalina extract showed similar strong Hepatoprotective effect as seen in Nifedipine (a drug widely known for its blood pressure lowering effect). It is further worthy of note that Vernonia amygdalina methanol and n-hexane extracts significantly decreased serum total bilirubin and serum conjugated bilirubin values in the experimental models as compared to negative control and standard value as seen in the study. It could be that Vernonia amygdalina possesses antioxidant and flavonoids capabilities.

Histological study of the kidney and liver in the control (Figure 3) showed normal kidney containing Bowman's capsular spaces, Glomerular tuft (Glo) containing mesengial cells, capillaries and mesengial matrix and Renal tubules (Rt). The liver also showed Cords of normal hepatocytes (Hep), Hepatic artery (HA) and portal vein (PV) and Sinusoids (sin) containing capillaries and Yon Kupffer cells [3,27]. Vernonia amygdalina have shown its protective potential on the tested liver and kidney. The cadmium chloride-induced hypertensive untreated group in figure 4 on the other hand shown a distorted kidney showing dilated capillaries and inflammatory cells. This implies that hypertension induced mechanism of action might occur through the tubular injury pathway [3]. Figure 5 and 6 shows histologically normal kidney for the control group and Vernonia amygdalina methanol group as seen in figures 8, 9 and 10 respectively.

Liver markers as comparing the Control group showed no significant difference in Table 4, but in Table 5 there was significant decrease in AST and Total bilirubin for Groups 4 and 5 (Vernonia amygdalina groups) and significant decrease in Total bilirubin when compare the hypertensive group with other groups. There was also significant decrease in Total bilirubin of Groups 4 and 5 as seen in Table 6 when the standard drug is compared with other groups. These liver markers as seen in the above Tables 5 , and 6 as compared with the control, hypertensive and standard drug groups have exhibited its protective, therapeutic and neutraceutical potentials in lowering Total bilirubin values of the study groups treated with Vernonia amygdalina. The test group which was treated with Vernonia amygdalina had no visible damage, this implies that treatment brought about tissue repair, hence methanol/n-hexane extracts of Vernonia amygdalina is capable of improving tissue damage in the condition of renal injury, left ventricular injury or endothelial injury that may result from hypertention [30, 3]

\section{Conclusion}

Vernonia amygdalina may have healing properties and potentials in the management of hypertension as shown in the treatment groups of the affected organs (heart, kidney and Liver). [27, 30, 31]

The findings of this study suggest that some biological activities of Nifedipine (standard drug) as seen in the study can be compared with that seen in Vernonia amygdalina for the treatment of hypertension. 


\section{Compliance with ethical standards}

\section{Acknowledgments}

We acknowledge the Head of the Department of Physiology for the enabled environment and approval for the use of Animal facility of the Department. Our appreciation also goes to Mr Ik for his kind assistance during the course of this study.

\section{Disclosure of conflict of interest}

There is no conflict of interest between the authors.

\section{Statement of ethical approval}

Ethical approval was sought and received from the Departmental Head and Committee.

\section{References}

[1] Gyebi G, Ocheje J, Ogunyemi O. Molecular docking studies on bioactive compounds from clove (Syzygium Aromaticum) on metabolic regulators in cancer. Salem University Journal of Life Sciences. 2019; 1: 1- 18.

[2] Kapadiya D, Dabhi B, Aparnathi K. Spices and Herbs as a Source of Natural Antioxidants for Food. Int. J. Curr. Microbiol. Appl. Sci. 2016; 5: 280-288.

[3] Henrrietta Ogadimma Nnadi, Vincent Ugochuwu Igbokwe. Nutraceuticals from Tetracapedium conophorum (Walnut) Protect against Cadmium Chloride induced Hypertension in Albino Rats. GSC Advanced Reseach and Reviews. 2022; 10(01): 031-041.

[4] Agumuo JK, Akajiaku LO, Alaka II, Taiwo M. Mineral and ant nutrients of fresh and squeeze -washed bitter leaf (Vernonia amygdalina) as affected by traditional de-bittering methods: European Journal of Food Sciences and Technology. 2016; 4(2): 21-30.

[5] Oshodi AA. Comparison of proteins, minerals and vitamin C content of some dried leafy vegetables. Parkistan Journal of Science and Industrial research. 1992; 35: 267-269.

[6] Imaga NOA, Bamigbetan DO. In vivo biochemical assessment of aqueous extracts of Vernonia amygdalina. International Journal of Nutrition and Metabolism. 2003; 5(2): 22-27.

[7] Farombi EO, Owoeye O. Antioxidative and Chemo protective properties of Vernonia amygdalina and Garcinia flavonoid. Int J Environ Res Public Health. 2011; 8(6): 2533-2555.

[8] Simbo DJ. An ethnobotanical survey of medicinal plants in Babungo, Northwest Region, Cameroon. J. of Ethnobiology and Ethnomedicine. 2010; 6: 8.

[9] Ndaeyo NU. Assessing the Contributions of homestead farming to food Security of Southesthern Nigeria. J. Agric. Soc. Sci. 2007; 3: 11-16.

[10] Kamatenesi-Mugisha M, Oryem-Origa H, Makawiti 00. Ethnopharmacological screening of Vernonia amygdalina and Cleome gynandra traditionally used in childbirth in Western Uganda. Proc 11th NAPRECA Symposium, Antanarivo, Madagascar. 2005; 12: 110-122.

[11] Kamatenesi-Mugisha M. Medicinal plants used in reproductive health care in Western Uganda: Documentation, phytochemical and bioactivity evaluation. PhD Thesis in Botany, Makerere University, Kampala, Uganda. Kambizi. 2004.

[12] Atangwho IJ, Ebong PE, Eteng MU, Eyong EU, Obi AU. Effect of Vernonia amygdalina Del. leaf on kidney function of diabetic rats. Int. J. Pharmacol. 2007; 3: 143-148.

[13] Atangwho IJ, Ebong PE, Eyong EU, Williams IO, Eteng MU, Egbung GE. Comparative chemical composition of leaves of some antidiabetic medicinal plants; Azadirachta indica, Vernonia amygdalina and Gongronema latifolium Afr. J. Biotech. 2009b; 8: 4685 - 4689.

[14] Ijeh II, Igwe KK, Ejike CECC. Effect of leaf aqueous extracts of Vernonia amygdalina Del. on contraction of mammary gland and uterus of guinea pig dams. J. Herbs Spices Med. Plants 16: in press. 2010. 
[15] Ijeh II, Obidoa O. Effect of dietary incorporation of Vernonia amygdalina Del. on AFB1-induced hepatotoxicity in weanling albino rats. Jamaican J. Sci. Tech. 2004; 15: 32-36.

[16] Ikenna KU, Okechukwu SO, Chidozie EA, Oliver, CO, Blessing EC, et al. Hypolipidaemic and renoprotective effects of Glycine max (soy bean) against lipid profile and renal biochemical alterations in hypercholesterolemia rat. Int J Biomed Res. 2016; 7(12): 822-828.

[17] Ikenna KU, Chidozie EA, Oliver CO, Eluke BC, Ikechukwu JC, et al. Effect of Soy (Glycine max) Against AlcoholInduced Biochemical Alteration in Liver of Male Albino Rat. Der Pharma Chemica. 2017; 9(16): 115-119.

[18] Orji OC, Agu CE, Uchendu IK, Nsonwu AC, Offor JS. Anti-diabetic and renal protective effect of the fruit juice of Citrus X Paradisi on alloxan induced diabetic male albino wistar rats. Der Pharmacia Lettre. 2016; 8(19): 32-38.

[19] Kingsley UI, Steven OO, Agu CE, Orji OC, Chekwube BE, et al. Anti-hyperlipidemic effect of crude methanolic extracts of Glycine max (soy bean) on high cholesterol diet-fed albino rats. J Med Allied Sci. 2017; 7(1): 34-40

[20] Uchendu IK, Agu CE, Orji OC, Nnedu EB, Arinze C, et al. Effect of Tomato (Lycopersicon Esculentum) Extract on Acetaminophen - Induced Acute Hepatotoxicity in Albino Wistar Rat. Bioequivalence and Bioavailability International Journal. 2018; 2(1): 000119.

[21] Anioke I, Okwuosa C, Uchendu I, Chijioke O, Dozie-Nwakile O, et al. Investigation into Hypoglycemic, Antihyperlipidemic, and Renoprotective Potentials of Dennettia tripetala (Pepper Fruit) Seed in a Rat Model of Diabetes. Hindawi BioMed Research Internationall. 2017; 11.

[22] Uchendu IK, Orji OC, Agu CE. Attenuation of glycerol-induced acute renal failure in albino rats by soy beans (Glycine max). International Journal of ChemTech Research. 2017; 10(12): 165-172.

[23] Senadeera S, Prasanna P, Jayawardana N, Gunasekara D, Senadeera P, Chandrasekara A. Antioxidant, physicochemical, microbiological, and sensory properties of probiotic yoghurt incorporated with various Annona species pulp. Heliyon. 2018; 4: e00955.

[24] Abosi AO, Raseroka BH. In vivo antimalarial activity of Vernonia amygdalina. Br. J. Biomed. Sci. 2003 ; 60: 89-91.

[25] Izevbigie EB, Byrant JL, Walker A. A novel natural inhibitor of extracellular signal-regulated kinases and human breast cancer cell growth. Exp. Biol. Med. 2004; 229: 163-169.

[26] Edward JR. Nutritional high blood pressure education programme working group report on hypertension in the elderly. Hypertension. 1994; 23(3): 274-285

[27] Ijeh II, Igwe KK, Ejike CECC. Current perspectives on the medicinal potentials of Vernonia amygdalina Del. J. of Medicinal Plants Research. 2011; 5(7): 1051-1061.

[28] Loscalzo J, Fauci AS, Braunwald E, Dennis L, Kasper H, Stephen L, Longo DL. Harrison's Principlaes of aianyernal Medicine. McGraw-Hill Medical Pubs. 2008.

[29] Blaustein MP, Zhang J, Chen L, Hamilton BP. How does salt retention raise blood pressure? Am J Physiol Regul Integr Comp Physiol. 2006; 290(3): R514-523.

[30] Satarug S, Nishijo M, Lasker JM, Edwards DJ, Moore MR. Kidney dysfunction and hypertention: role for cadmium p450 and heme oxgenases? Tohoku J. Exp Med. 2006; 208: 179-202.

[31] Igile GO, Oleszek W, Jurzysta M, Burda S, Fasunso M, et al. Flavonoids from Vernonia amygdalina and their antioxidant activities. J Agric Food Chem. 1994; 42(11): 2445-2448. 